\title{
WIKIPEDIA
}

\section{Kinh tế Việt Nam - Thăng trầm và Đột phá}

Bách khoa toàn thư mở Wikipedia

Kinh tế Việt Nam - Thăng trầm và Đột phá là tác phẩm của hai tác giả Phạm Minh Chính và Vương Quân Hoàng, do Nhà xuất bản Chính trị Quốc gia - Hà Nội xuất bản lần đầu vào tháng 5 năm 2009. Tác phẩm này là một công trình nghiên cứu khoa học về kinh tế Việt Nam trong thời kỳ khủng hoảng kinh tế và hội nhập, và là công trình nghiên cứu một giai đoạn phát triển sôi động bậc nhất của nền kinh tế Việt Nam thời kỳ đổi mới, viết về nền kinh tế của Việt Nam với trọng tâm nghiên cứu đặt vào hệ thống tài chính - tín dụng - tiền tệ; tác phẩm này mô tả toàn cảnh nền kinh tế Việt Nam được trình bày với mong muốn để lại trong độc giả những suy nghĩ về hành trình tiếp tục chinh phục nền kinh tế toàn cầu, cùng giấc mơ nước Việt Nam phát triển và thịnh vượng.

Cuốn sách được Nhà xuất bản Chính trị Quốc gia Sự thật xuất bản lần thứ hai vào tháng 7 năm 2021, sau hơn 12 năm kể từ khi phát hành lần đầu. Lời giới thiệu trên trang web cuốn sách xuất bản lần hai:[1]

Cuốn sách được xuất bản lần đầu vào năm 2009 và xuát bản lần thư hai vào tháng 7/2021. Đây là một trong nhüng cuốn sách đầu tiên viết về lịch sử kinh tế Việt Nam sư dụng cách tiếp cận mói, áp dụng nhiều công cu phân tích kinh tế - tài chính mói trong nghiên cúu, đánh giá các sự kiện, vấn đề kinh tế của thế giới và Việt Nam.

Trong lần xuất bản thư hai này, Nhà xuất bản Chính trị quốc gia Sự thật giữ nguyên nhũng phân tích, nhận định, đánh giá của các tác giả về các sư kiện, về các vấn đề kinh tế được xuất bản trong lần xuất bản thư nhất, tôn trọng nhũng ý kiến đóng góp có giá trị lịch sư của các tác giả trong nghiên cúu kinh tế Việt Nam.

\section{Kinh tế Việt Nam Thăng trầm và Đột phá}

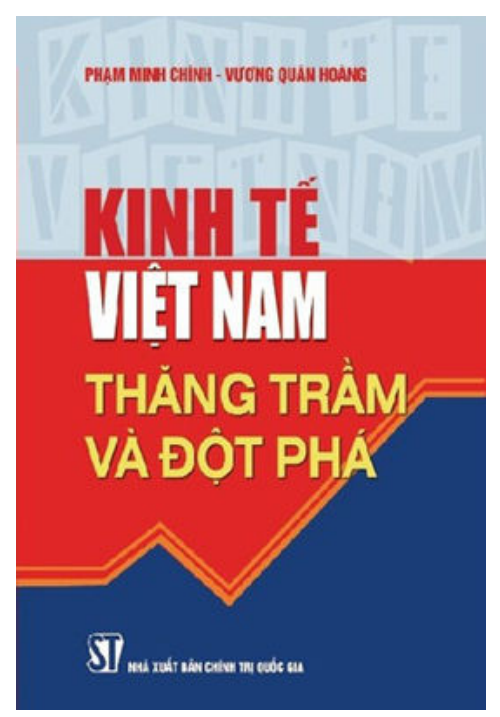

Bìa sách in lần đầu tiên, tháng 5 năm 2009

\section{Thông tin sách}

Tác giả

Phạm Minh Chính, Vương Quân Hoàng

Quốc gia

Việt Nam

Ngôn ngữ

Tiếng Việt

Chủ đề

Sách kinh tế

Nhà xuất bản

Chính trị Quốc gia

Ngày phát hành

ISBN
Tháng 5 năm 2009

9786045769478

\section{Mục lục}

\section{Bố cục}

Nội dung

Đánh giá

Thông tin tác giả

\section{Chú thích}




\section{Bố cục}

Cuốn sách với khổ sách: 15x22, dày 538 trang; Sách viết về nền kinh tế của Việt Nam với trọng tâm nghiên cứu đặt vào hệ thống tài chính - tín dụng - tiền tệ, bao gồm 3 phần với 13 chương:

Chương 1. Sóng gió;

Phần 1: Thăng trầm, gồm 5 chương:

Chương 2. Những hạt mầm đầu tiên,

Chương 3. Cam go độc lập tiền tệ: 1945-1954,

Chương 4. Kinh tế Việt Nam thời kỳ 1955-1985,

Chương 5. Kinh tế tài chính thời kỳ Đổi Mới 1986-2000,

Chương 6. Đặc trưng biến động kinh tế trong quá trình chuyển đổi;

Phần 2: Đột phá, gồm 4 chương:

Chương 7. Đột phá tư duy kinh tế: Đổi Mới,

Chương 8. Hệ thống ngân hàng hai cấp,

Chương 9. Tài sản và Thị trường,

Chương 10. Thị trường chứng khoán;

Phần 3: Vấn đề và hiện tưọng, gồm 3 chương:

Chương 11. Một số vấn đề của các thị trường tài sản,

Chương 12. Quản lý nhà nước đối với các thị trường và tài sản,

Chương 13. Việt Nam hội nhập toàn cầu. [2]

\section{Nội dung}

Trọng tâm nghiên cứu của "Kinh tế Việt Nam - Thăng trầm và đột phá" là hệ thống thị trường và phương tiện kiểm soát tài chính tiền tệ, cuốn sách tập trung nghiên cứu sâu về thị trường bất động sản, thị trường vàng và đô la $M y ̃$, thị trường chứng khoán Việt Nam. Tác giả của công trình nghiên cứu đã cung cấp một số lượng lớn thông tin giá trị với những nhận định sắc sảo, có giá trị gợi mở suy nghĩ về các thị trường này, và cũng đã phân tích về các vấn đề và hiện tượng đặc trưng có tính phổ quát trong nền kinh tế: Bong bóng tài sản tồn tại cả với thị trường bất động sản và thị trường chứng khoán. Hiện tượng "bầy đàn" thể hiện đậm nét qua hình ảnh chen nhau mua vàng vào lúc lên giá, với việc vay mượn mua chứng khoán khi chỉ số VN-Index ở đỉnh, thế rồi, lại đổ xô đi đặt lệnh bán khi chỉ số giá sụt giảm.[3]

\section{Đánh giá}

Sau hơn 12 năm phát hành, "Kinh tế Việt Nam - Thăng trầm và đột phá" được nhiều học giả sử dụng, trích dẫn trong các nghiên cứu tiếp theo.

66 Cuốn sách này, cùng với một vài cuốn sách khác, chứng tỏ cần có cách tiếp cận mới, các công cu mới và hệ tri thức mới để mổ xẻ, phân tích các quá trình thực tiễn. Bản thân cuốn sách được coi là một sự khởi động thật sự, rất đáng trân trọng cho quá trình đó. Đẩy mạnh hơn quá trình này là một cách, một nội dung hội nhập quốc tế - hội nhập khoa học, đồng thời là cách thúc đẩy sự phát triển trong hội nhập của nền kinh tế nước ta. Vi tất cả những lẽ đó "Kinh tế Việt Nam - thăng trầm và đột phá" là cuốn sách cần và 
nên đọc.

—Trần Đình Thiên - Phó Giáo sư, TS, Quyền Viện trưởng, Viện Kinh tế Việt Nam. [4]

Đến tháng 7 năm 2021, Nhà xuất bản Chính trị Quốc gia Sự thật đã xuất bản lần thứ hai, với nội dung được giữ nguyên như lần xuất bản đầu tiên.

\section{Thông tin tác giả}

- Phạm Minh Chính - Phó Giáo sư, Tiến sĩ;

- Vương Quân Hoàng - Tiến sĩ, Đại học Tổng hợp Bruxelles, Belgium.[5]

\section{Chú thích}

1. ^ NXB Chính trị Quốc gia Sự thật (2021). "Thông tin sách Kinh tế Việt Nam: Thăng trầm và Đột phá”. Nxb Chính trị Quốc gia. Đã bỏ qua văn bản "https://www.nxbctqg.org.vn/kinh-te-viet-namthang-tram-va-dot-pha-55.html" (trợ giúp)

2. ^ Nhà xuất bản Chính trị quốc gia giới thiệu. "Kinh tế Việt Nam: Thăng trầm và Đột phá” (bằng tiếng Việt). Nhà xuất bản Chính trị quốc gia - Sự thật. Truy cập ngày 7 tháng 12 năm 2010. Kiểm tra giá trị | url lưu trữ= (trợ giúp)

3. ^ Chính, Phạm Minh; Hoàng, Vương Quân (ngày 27 tháng 5 năm 2009). Kinh tế Việt Nam: Thăng trầm và đột phá. Nhà xuất bản Chính trị Quốc gia Sự thật. ISBN 9786045769478.

4. ^ Trần Đình Thiên (ngày 28 tháng 5 năm 2009). "GIỚI THIẸU SÁCH "Kinh tế Việt Nam - Thăng trầm và đột phá" " (bằng tiếng Việt). Tạp chí Cộng sản. Truy cập ngày 7 tháng 12 năm 2010. Kiểm tra giá trị | url lưu trữ= (trợ giúp)

5. ^ "TS. Vương Quân Hoàng - Université Libre de Bruxelles". Truy cập ngày 12 tháng 12 năm 2020.

Lấy từ "https://vi.wikipedia.org/w/index.php?title=Kinh_tế_Việt_Nam_-_Thăng_trầm_và_Đột_phá\&oldid=66159254"

\section{Trang này được sửa đổi lần cuối vào ngày 20 tháng 9 năm 2021 lúc 17:30.}

Văn bản được phát hành theo Giấy phép Creative Commons Ghi công-Chia sẻ tương tự; có thể áp dụng điều khoản bổ sung. Với việc sử dụng trang web này, bạn chấp nhận Điều khoản Sử dụng và Quy định quyền riêng tư.

Wikipediaß là thương hiệu đã đăng ký của Wikimedia Foundation, Inc., một tổ chức phi lợi nhuận. 